\title{
SPONTANEOUS GASTRIC PERFORATION IN A NEWBORN
}

(Case Report)

\author{
Lt Col M K BEHERA ${ }^{*}$, Lt Col KM HARIKRISHNAN ${ }^{+}$, \\ Maj SUNIL JAIN
}

MJAFI 1998; 54 : 353-354

KEYWORDS: Neonate; Pneumoperitoneum; Spontaneous gastric perforation.

\section{Introduction}

$\mathbf{S}$ pontaneous gastric perforation is a rare occurrence in the newborn [1]. Only about 200 such cases have been reported in the literature $[2,3]$. The presence of free air in the peritoneal cavity may be secondary to perforation anywhere in the gastrointestinal tract and is a surgical emergency. This condition carries a high mortality and the pathogenesis is greatly debated. Prompt surgical intervention is rewarding. We are reporting this case as it is rare and requires a high index of suspicion for its early diagnosis and management.

\section{Case Report}

A male neonate weighing $1.5 \mathrm{~kg}$ was born as the second of a twin delivery to a primipara at 34 weeks of gestation. The baby had mild asphyxia at birth and was resuscitated in the labour room by tactile stimulation and suction of mouth and oropharynx. Subsequently, the baby was managed in the neonatal intensive care unit with intravenous fluids, vitamin $\mathrm{K}$, and prophylactic antibiotics ampicillin and gentamicin being a preterm low birth weight baby. Baby passed urine and meconium and progressed satisfactorily with stable vital parameters for 2 days. On the third day, the baby's general condition suddenly deteriorated and he developed distension of abdomen with respiratory distress. Chest was clinically normal with good air entry. Heart rate was $140 / \mathrm{min}$, respiratory rate was $68 / \mathrm{min}$, abdomen was distended and bowel sounds were not audible, and the colour of gastric aspirate was coffec ground. At this stage the baby was managed with amikacin, cefotaxime, along with intravenous fluids, ranitidine and other symptomatic and supportive therapy. Investigations revealed $\mathrm{Hb} 17 \mathrm{gm}$ $\%$, TLC 9,600/cu mm, DLC P52 L42 M2 E4. Peripheral smear study did not show toxic granules or band form leucocytes. Blood culture was sterile. Blood sugar, urea, serum electrolytes, platelet count, bleeding and clotting time were within normal limits. Chest and abdominal radiographs showed free gas under the diaphragm, and all the viscera were seen to be pushed medially. producing the typical saddle bag appearance (Fig 1).

A diagnosis of pneumoperitoneum due to gastrointestinal perforation was made and urgent laparotomy undertaken. Air gushed out on opening the abdomen. One $\mathrm{cm}$ long linear perforation with ragged edges was located in the anterior wall in the greater curva- ture of stomach. The surrounding stomach wall was ischaemic. Posterior aspect of stomach was also inspected and tear excluded. Resection of the ischaemic edges was done and the perforation was closed in two layers. Peritoneal toilet was done and the abdomen was closed. The baby made an uneventful recovery and was discharged on the 15 th post operative day.

\section{Discussion}

Spontaneous gastric perforation is a rare entity in newborns, usually occurring in the first five days of

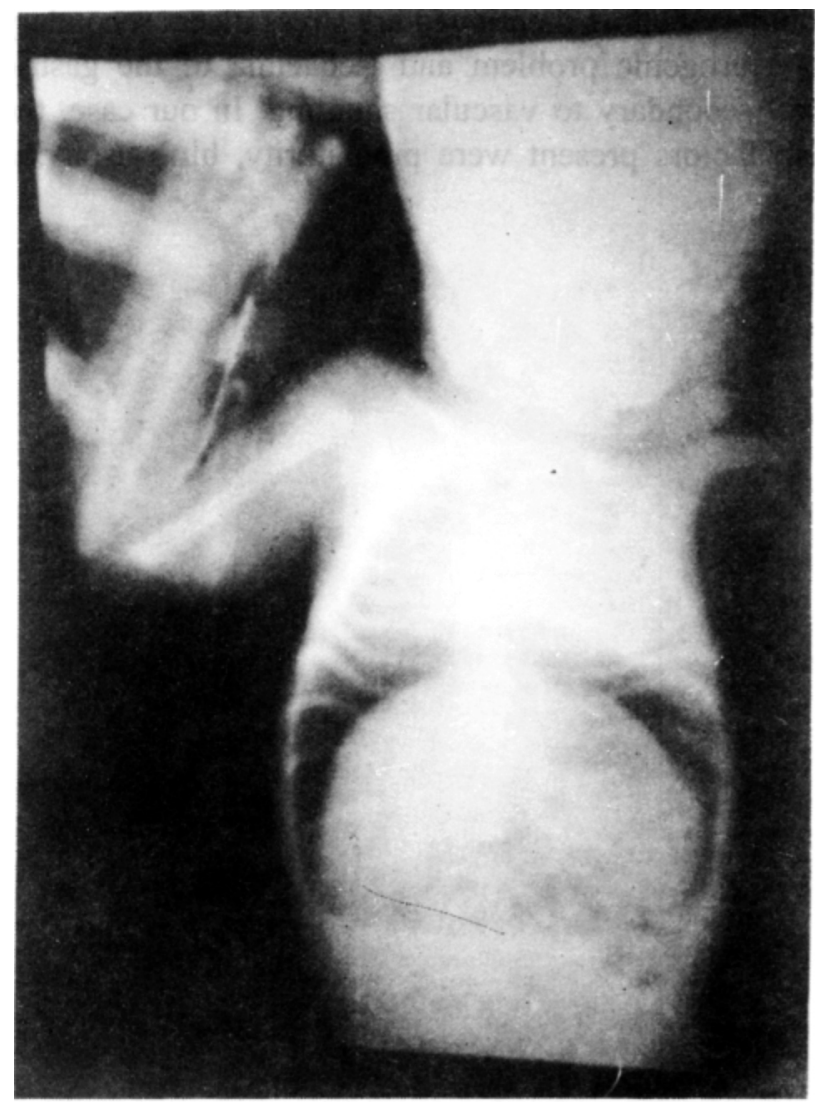

Fig. 1: $X$-ray abdomen ereet film showing free air under the diaphragm. The abdominal viscera are displaced medially producing the 'saddle bag' appearance

\footnotetext{
Classified Specialist Pacdiatrics, MH Secunderabad-500015 ${ }^{+}$Classified Specialist Surgery and Gastroenterology ", Postgraduate Trainee,
} Department of Paediatrics. Command I lospital (EC), Calcutta. 
life with highest reported incidence on the third day of life $[4,5]$. The commonly associated prenatal and perinatal risk factors as reported in order of frequency are prematurity, respiratory distress syndrome, birth asphyxia and resuscitation, premature rupture of membranes, breech delivery, caesarian delivery and twin delivery $[4,6]$. Sudden respiratory distress, distension of the abdomen and gastric haemorrhage have been reported as the predominant symptoms $[1,2,4]$

In an infant with pneumoperitoneum, the whole gastrointestinal tract requires systematic investigation to exclude gastric perforation, necrotising enterocolitis, Hirschprung's disease or other ischaemic insults to the intestines.

Pathogenesis of gastric perforation is greatly debated. Congenital absence or deficiency of musculature of the gastric wall has been suggested as a possible cause $[1,2]$ but this explanation is questionable. The apparent absence of musculature at the margin of the perforation probably represents retraction of the muscles of an overdistended stomach with ballooning of the mucosa between the muscle fibers. Other contributory factors mentioned are stress ulcers secondary to neurogenic problem and ischaemia of the gastric wall secondary to vascular shunting. In our case, the risk factors present were prematurity, birth asphyxia and twin delivery. the perforation occurred on third day and was located on the anterior wall of the body of the stomach, as reported by most authors $[2,3]$. Most commonly the perforation is seen as a linear tear on the greater curvature and measures between 0.5 to $8 \mathrm{~cm}[2,4]$.

Prompt surgical intervention with primary repair of the gastric tear is the recommended management and any delay in surgery results in high mortality.

\section{REFERENCES}

1. Avery GB. Fletcher MA. Macdonald MG In : Neonatology, 4th ed. Philadelphia: JB Lippincott Company, 1994:613,92930.

2. Houck WS, Griffin JA. Spontaneous linear tear of the stomach in the neworn infant. Ann Surg 1981;193:763-7.

3. Gathwala G, Rattan KN, Abrol P, Sodhi D. Spontaneous Gastric perforation in a neonate. Indian Pediatr 1994; 31:1013-5.

4. Holgersen LO. The etiology of spontaneous gastric perforation of the newborn: A re-evaluation. J Pediatr Surg 1981;16:608-13.

5. Hood JH. Clinical considerations of intestinal gas. Ann Surg 1966;163:359-66.

6. Prabhakar G, Agarwal LD, Shukla A, et al. spontaneous gastrointestinal perforation in the neonate. Indian Pediatr 1991;28:1277-80. 